Arab Univ. J. Agric. Sci., Ain Shams Univ., Cairo, 13(3), 641-668, 2005

\title{
IDENTIFICATION OF EIGHT HALOTOLERANT STREPTOMYCETE ISOLATES USING A SUGGESTED NUMERICAL TAXONOMY
}

[42]

\author{
Mohamed Sonya, H. ${ }^{1}$; E.A. Saleh ${ }^{2}$ and M.M. Zaki
}

\begin{abstract}
A numerical method was suggested for the identification of eight local halotolerant streptomycete isolates. Cultural, morphological, physiological and antagonistic characteristics of those isolates were determined. Arbitrary scoring of these characters for the eight unknown isolates and those of the more related known Streptomyces species in the key of Pridham and Tresner (1974) was given and resulted 58 characteristic units. The degree of similarity was determined using the Dice coefficient method and clustering was achieved using the unweighted pair group method average (UPGMA) algorithm. Using this numerical method, six out of the eight Streptomyces isolates, i.e., ST08, ST09, ST11, ST13, ST14 and ST15 were identified as $S$. longisporus, $S$. janthinus, $S$. griseochromogenes, $S$. antibioticus $S$. baarnensis and S. albolongus with 100, 95.8, 95.0, 92.8, 95.0 and 91.1\%, respectively. Isolates ST10 and ST12 were duplicate of S. echinatus with similarities of 93.3 and $94.6 \%$, respectively. Application of the suggested numerical taxonomy on the 14 known Streptomyces species revealed that these species fell into three major clusters based on their color of aerial mycelia.
\end{abstract}

Key words: Streptomyces, Numerical identification, Halotolerant, Characteristic units, Taxonomy

\section{INTRODUCTION}

Genus Streptomyces comprises, by far, the largest number of species of actinomycetes now known to occur in nature (Williams et al 1989). Many investigators throughout the world are isolating cultures of streptomycetes from soils (Goodfellow et al 1987; Srinivasan et al 1991 and Mohamed et al 2001) and other substrates (Saleh et al 1990 and Mohamed et al 2000) and studying their cultural, physiological and biochemical activities (Abdel-Fattah, 2005).

Goodfellow (1967) described a numerical taxonomy method and cultures accordingly. Numerical taxonomy methods were thereafter applied to the

1- Agricultural Microbiology Department, Institute of Soil, Water and Environment Research, Agricultural Research Center, Giza, Egypt.

2- Agricultural Microbiology Department, Faculty of Agriculture, Ain Shams University, Shoubra El-Kheima, Cairo, Egypt 
Arab Univ. J. Agric. Sci., Ain Shams Univ., Cairo, 13(3), 641-668, 2005

genus Streptomyces by Paszkiewicz (1972); Kurylowicz et al (1975) and Goodfellow et al (1992). Goodfellow et al (1979) used a numerical system to classify 156 Actinomadura strains, and found marker strains of related taxa, and related isolates from bagasse and fodder via the numerical phenetic analyses using 90 unit characters. Williams et al (1983) suggested a standard numerical classification of 475 strains, of which 394 type cultures of Streptomyces, and 14 other actinomycete genera.

The present study suggests a numerical taxonomy method for eight Streptomyces isolates by comparing their phylophenetic characters with their corresponding strains in the eighth edition of Bergey's Manual of Determinative Bacteriology (Pridham and Tresner, 1974).

\section{MATERIAL AND METHODS}

\section{Streptomyces isolates}

Eight-halotolerant streptomycete isolates belonging to white (ST08, ST14 and ST15); red (ST09) and gray (ST10, ST11, ST12, and ST13) series were kindly provided from the Department of Agricultural Microbiology, Institute of Soil, Water and Environment Research, ARC, Giza, Egypt.

\section{Characterization of Streptomyces isolates}

Cultural and morphological characteristics of Streptomyces isolates under investigation were determined as proposed by Pridham and Tresner (1974) using the media and methods of The International Streptomyces Project (ISP) as described by Shirling and Gottlieb (1966). In addition, antagonistic activities of the tested Streptomyces isolates against 2 fungi, 2 yeasts and 5 bacteria (kindly provided by Cairo MIRCEN, Faculty of Agriculture, Ain Shams University) were determined as described by Mohamed et al (2001). Salt tolerance range was also studied using four $\mathrm{NaCl}$ concentrations, i.e., 3.5, 7.0, 10 and $13 \%$ as mentioned by Mohamed $\boldsymbol{e t}$ al (2000). Chain type and spore surface of the Streptomyces isolates were determined as recommended by Pridham and Tresner (1974) using the light and electron microscopy, respectively. The abilities of the isolates to produce melanoid pigment, growth on Czapek's medium, to produce diffusible pigments, to tolerate streptomycin $\left(4 \mu \mathrm{g} \mathrm{ml}^{-1}\right)$ and to utilize nine carbon compounds were studied as described by Saleh $\boldsymbol{e t}$ al (1990).

\section{Numerical identification of Streptomyces}

Characters of Streptomyces reported in the key of Pridham and Tresner (1974) in the eighth edition of Bergey's Manual of Determinative Bacteriology

1- Agricultural Microbiology Department, Institute of Soil, Water and Environment Research, Agricultural Research Center, Giza, Egypt.

2- Agricultural Microbiology Department, Faculty of Agriculture, Ain Shams University, Shoubra El-Kheima, Cairo, Egypt 
Identification of streptomycete isolates by numerical taxonomy

were divided into two parts. Part I

represents the main taxonomical

characters that included color of aerial

mycelium, spore-chain, melanoid

pigment, spore surface and utilization of carbon compounds. Part II includes the other assisted characters for streptomycetes classification, i.e., growth on Czapek's medium, anti-bacterial and - fungal activities, sensitivity to streptomycin, color of substrate mycelium, diffusible pigments and $\mathrm{NaCl}$ tolerance.

Suggested scoring of each of the previous characters (main and assisted) was given 1 unit if present or 0 unit if absent (Table 1). Relative importances for each of these characters were arbitrary 
Arab Univ. J. Agric. Sci., Ain Shams Univ., Cairo, 13(3), 641-668, 2005

Table 1. Arbitrary numerical scoring for the characters of Streptomyces isolates as present (1) or absent (0), for their identification and classification.

\begin{tabular}{|c|c|c|}
\hline Characters for streptomycetes identification & Present & Absent \\
\hline \multicolumn{3}{|c|}{ I-Main taxonomical characters } \\
\hline \multicolumn{3}{|l|}{ a-Color of aerial mycelium (22 units) } \\
\hline Violet & $1(1)$ & 0 \\
\hline Green & $1(4)$ & 0 \\
\hline Yellow & $1(7)$ & 0 \\
\hline Blue & $1(10)$ & 0 \\
\hline White & $1(13)$ & 0 \\
\hline Red & $1(16)$ & 0 \\
\hline Gray & $1(22)$ & 0 \\
\hline \multicolumn{3}{|l|}{ b-Spore-chain (4 units) } \\
\hline RA & $1(2)$ & 0 \\
\hline $\mathrm{S}$ & $1(2)$ & 0 \\
\hline RA-S & $1(3)$ & 0 \\
\hline RF & $1(4)$ & 0 \\
\hline c-Melanoid pigment ( 1 unit) & $1(1)$ & 0 \\
\hline \multicolumn{3}{|l|}{ d-Spore surface (5 units) } \\
\hline $\mathrm{SM}$ & $1(5)$ & 0 \\
\hline WTY & $1(1)$ & 0 \\
\hline SPY & $1(3)$ & 0 \\
\hline $\mathrm{H}$ & $1(2)$ & 0 \\
\hline \multicolumn{3}{|l|}{ e-Utilization of carbon compounds (17 units) } \\
\hline No carbon & $1(1)$ & 0 \\
\hline D-Glucose & $1(1)$ & 0 \\
\hline D-Xylose & $1(1)$ & 0 \\
\hline L-Arabinose & $1(1)$ & 0 \\
\hline L-Rhamnose & $1(2)$ & 0 \\
\hline D-Fructose & $1(2)$ & 0 \\
\hline n & $1 \mathrm{~m}$ & $n$ \\
\hline
\end{tabular}

1- Agricultural Microbiology Department, Institute of Soil, Water and Environment Research, Agricultural Research Center, Giza, Egypt.

2- Agricultural Microbiology Department, Faculty of Agriculture, Ain Shams University, Shoubra El-Kheima, Cairo, Egypt 
Identification of streptomycete isolates by numerical taxonomy

Table 1. Cont.

\begin{tabular}{|c|c|c|}
\hline Characters for streptomycetes identification & Present & Absent \\
\hline \multicolumn{3}{|c|}{ II- Other assisted characters } \\
\hline \multicolumn{3}{|l|}{ f- Growth on Czapek's medium (5 units) } \\
\hline Fair & $1(1)$ & 0 \\
\hline Poor & $1(2)$ & 0 \\
\hline Moderate & $1(3)$ & 0 \\
\hline Good & $1(4)$ & 0 \\
\hline Excellent & $1(5)$ & 0 \\
\hline g- Antibacterial activity (2 units) & $1(2)$ & 0 \\
\hline h- Antifungal activity (2 units) & $1(2)$ & 0 \\
\hline Subtotal & $58(1)$ & $\mathbf{0}$ \\
\hline i- Sensitivity to streptomycin (1 uint) & $1(1)$ & 0 \\
\hline j-Color of substrate mycelium (1 unit) & $1(1)$ & 0 \\
\hline k- Diffusible pigments (1 unit) & $1(1)$ & 0 \\
\hline \multicolumn{3}{|l|}{ 1- $\mathrm{NaCl}$ tolerance (4 units) } \\
\hline $0-7 \%$ & $1(2)$ & 0 \\
\hline $0-10 \%$ & $1(3)$ & 0 \\
\hline$>10 \%$ & $1(4)$ & 0 \\
\hline Total units & \multicolumn{2}{|c|}{$1(65)$} \\
\hline
\end{tabular}

suggested according to their importance in the identification of streptomycetes. Accordingally, color of aerial mycelium was given a maximum of $\mathbf{2 2}$ units, type of spore chain 4 units, melanoid pigments 1 unit and spore surface $\mathbf{5}$ units. Utilization of carbon compounds was given 17 units, growth on Czapek's medium $\mathbf{5}$ units, antibacterial activity $\mathbf{2}$ units, antifungal activity $\mathbf{2}$ units, sensitivity to streptomycin 1 unit, color of substrate mycelium 1 unit, diffusible pigments 1 unit and $\mathrm{NaCl}$ tolerance 4 units. Within each character, its units were distributed according to frequency distribution of sub-characters. For example, gray, red, white, blue, yellow, green, and violet aerial mycelia were given $22,16,13,10$, 7, 4 and 1 units, respectively.

Cultural, morphological and assisted characters of the eight Streptomyces isolates were compared with those of the most similar 14 Streptomyces species in the key of Pridham and Tresner (1974). The similarity matrix between the experimental and identified species, in 
Pridham and Tresner (1974), was determined by Dice Coefficient method. In addition clustering of all characters was determined by the unweighted pair group method with average (UPGMA) algorithm (Sneath and Sokal, 1973). Analyses were done using the Diversity Data base ${ }^{\mathrm{TM}}$ Version 2.0 from Bio-Rad.

Suggested numerical identification was based on the four characteristics, which are used for streptomycetes identification in Pridham and Tresner (1974). In addition, some of the assisted characters, i.e., growth on Czapek's medium, anti- bacterial and -fungal activities due to their use in the identification of more than $60 \%$ of Streptomyces species. The unit character for the main characters was 49 , and those of selected assisted characters were 9 units making a total of 58 unit characters. The rest of assisted characters, namely, sensitivity to streptomycin, color of substrate mycelium, diffusible pigments, and $\mathrm{NaCl}$ tolerance are not usually reported for identification of the majority of Streptomyces species in the key of Pridham and Tresner (1974).

\section{RESULTS AND DISCUSSION}

\section{Characterization of the Streptomyces isolates}

Characterization of white, red and gray streptomycete isolates are given in
Table (2), Figures (1), (2) and could be represented as follows:

\section{White Streptomyces isolates}

The two white Streptomyces isolates, namely, ST14 and ST15 were characterized with RF chain spores and smooth surface spores, while the third (ST08) had RA chain spores and spiny spore surface. Both of ST08 and ST15 were able to produce melanoid pigment while, ST14 did not. Regarding the utilization of carbon compounds, ST08 utilized all the carbon compounds as sole sources of carbon. On the other hand, ST14 and ST15 varied in their utilization of raffinose and sucrose, and did not utilize mannitol. The three isolates showed good or excellent growth on Czapek's medium. The ST14 and ST15 isolates showed white aerial mycelium and only showed antibacterial activities. On the other hand, ST08 showed colorless aerial mycelium and no antagonistic activities against the bacterial or fungal test organisms. Variation was also observed in the sensitivity of these isolates to streptomycin.

\section{Red Streptomyces isolates}

The red Streptomyces isolate, namely, ST09 was characterized with RA or spiny chains spore with smooth surface, producing melanoid pigments, utilizing of

1- Agricultural Microbiology Department, Institute of Soil, Water and Environment Research, Agricultural Research Center, Giza, Egypt.

2- Agricultural Microbiology Department, Faculty of Agriculture, Ain Shams University, Shoubra El-Kheima, Cairo, Egypt 
Identification of streptomycete isolates by numerical taxonomy

all carbon compounds as sole source of carbon, good growth on Czapek's medium, yellow substrate mycelium, not sensitive to streptomycin, antagonistic activity against the bacterial test organisms.

\section{Gray Streptomyces isolates}

Three of the four gray Streptomyces isolates, namely, ST10, ST11 and ST12 were characterized with RA or spiny chain spores, while the fourth (ST13) showed RF chain spores with smooth spores, and all of them produced melanoid pigment. The color of their aerial mycelia varied between yellow to grayish yellow. They showed variation in 
Arab Univ. J. Agric. Sci., Ain Shams Univ., Cairo, 13(3), 641-668, 2005

Table 2. Taxonomical characters of eight halotolerant streptomycete isolates according to the key of Pridham and Tresner (1974) .

\begin{tabular}{|c|c|c|c|c|c|c|c|c|}
\hline $\begin{array}{l}\text { Streptomyces } \\
\text { isolates }\end{array}$ & \multicolumn{8}{|c|}{ I- Main taxonomical characters } \\
\hline & \multicolumn{2}{|c|}{$\begin{array}{l}\text { a-Color of aerial } \\
\text { mycelium }\end{array}$} & \multicolumn{2}{|r|}{ b-Spore-chain* } & \multicolumn{2}{|c|}{$\begin{array}{l}\text { c-Melanoid } \\
\text { pigment }\end{array}$} & \multicolumn{2}{|c|}{ d-Spore surface } \\
\hline ST08 & \multicolumn{2}{|c|}{ white } & \multicolumn{2}{|r|}{ RA } & \multicolumn{2}{|r|}{+} & \multicolumn{2}{|r|}{ spiny } \\
\hline ST09 & \multirow{2}{*}{\multicolumn{2}{|c|}{ red }} & \multicolumn{2}{|r|}{ RA-S } & \multicolumn{2}{|r|}{+} & \multicolumn{2}{|r|}{ spiny } \\
\hline ST10 & & & \multicolumn{2}{|r|}{ RA } & \multicolumn{2}{|r|}{+} & \multicolumn{2}{|r|}{ spiny } \\
\hline ST11 & \multicolumn{2}{|c|}{ gray } & \multicolumn{2}{|r|}{ RA-S } & \multicolumn{2}{|r|}{+} & \multicolumn{2}{|r|}{ spiny } \\
\hline ST12 & \multicolumn{2}{|c|}{ gray } & \multicolumn{2}{|r|}{ RA } & \multicolumn{2}{|r|}{+} & \multicolumn{2}{|r|}{ spiny } \\
\hline ST13 & \multicolumn{2}{|c|}{ gray } & \multicolumn{2}{|r|}{$\mathrm{RF}$} & \multicolumn{2}{|r|}{+} & \multicolumn{2}{|r|}{ smooth } \\
\hline ST14 & \multicolumn{2}{|c|}{ white } & \multicolumn{2}{|r|}{$\mathrm{RF}$} & & - & & smooth \\
\hline ST15 & & hite & & $\mathrm{RF}$ & & + & & smooth \\
\hline & & & e-Utili & zation of carbon & ompounds & & & \\
\hline $\begin{array}{l}\text { Carbon } \\
\text { sources }\end{array}$ & & & & Streptomyces & solates & & & \\
\hline & ST08 & ST09 & ST10 & ST11 & ST12 & ST13 & ST14 & ST15 \\
\hline No carbon & - & - & - & - & - & - & - & - \\
\hline D-Glucose & + & + & + & + & + & + & + & + \\
\hline D-Xylose & + & + & + & + & + & + & + & + \\
\hline L-Arabinose & + & + & + & + & + & + & + & + \\
\hline L-Rhamnose & + & + & + & - & + & + & + & + \\
\hline D-Fructose & + & + & + & + & + & - & + & + \\
\hline Raffinose & + & + & - & + & - & + & - & + \\
\hline D-Mannitol & + & + & + & + & + & + & - & - \\
\hline i-Inositol & + & + & + & + & + & + & + & + \\
\hline Sucrose & + & + & - & + & - & - & + & - \\
\hline & & II- C & Other & assisted characte & & & & \\
\hline Isolates & $\begin{array}{l}\text { Growth } \\
\text { on } \\
\text { Czapek's } \\
\text { medium }\end{array}$ & $\begin{array}{c}\text { Antagonisti } \\
\text { activity }\end{array}$ & & $\begin{array}{l}\text { Sensitivity to } \\
\text { streptomycin }\end{array}$ & $\begin{array}{l}\text { Color of } \\
\text { substrate } \\
\text { mycelium }\end{array}$ & $\begin{array}{l}\text { Diffu } \\
\text { pigm }\end{array}$ & $\begin{array}{l}\text { sible } \\
\text { ents }\end{array}$ & $\begin{array}{c}\mathrm{NaCl} \\
\text { tolerance } \\
\text { (Up to } \\
10 \% \text { ) }\end{array}$ \\
\hline ST08 & Excellent & - & & - & Colorless & s & & + \\
\hline ST09 & Good & Anti-bacteric & & - & Yellow & - & & + \\
\hline ST10 & Moderate & - & & + & $\begin{array}{l}\text { Grayish } \\
\text { yellow }\end{array}$ & - & & + \\
\hline ST11 & Excellent & Anti-bacteric & & - & Yellow & - & & + \\
\hline ST12 & Good & Anti-bacteric & & + & $\begin{array}{l}\text { Grayish } \\
\text { yellow }\end{array}$ & - & & + \\
\hline
\end{tabular}

1- Agricultural Microbiology Department, Institute of Soil, Water and Environment Research, Agricultural Research Center, Giza, Egypt.

2- Agricultural Microbiology Department, Faculty of Agriculture, Ain Shams University, Shoubra El-Kheima, Cairo, Egypt 
9

Identification of streptomycete isolates by numerical taxonomy

*RA: spore chain in the form of open loops, hooks or greatly extended coils of wide. RF: spores in straight $(\mathrm{R})$ or flexuous $(\mathrm{F})$ chains. S: spira; spore chain in form of hooks, open loops and coils

Figure 1. Microphotographs of spore chain of some Streptomyces isolates (x-400).

Arab Univ. J. Agric. Sci., 13(3), 2005 
Mohamed; Saleh and Zaki
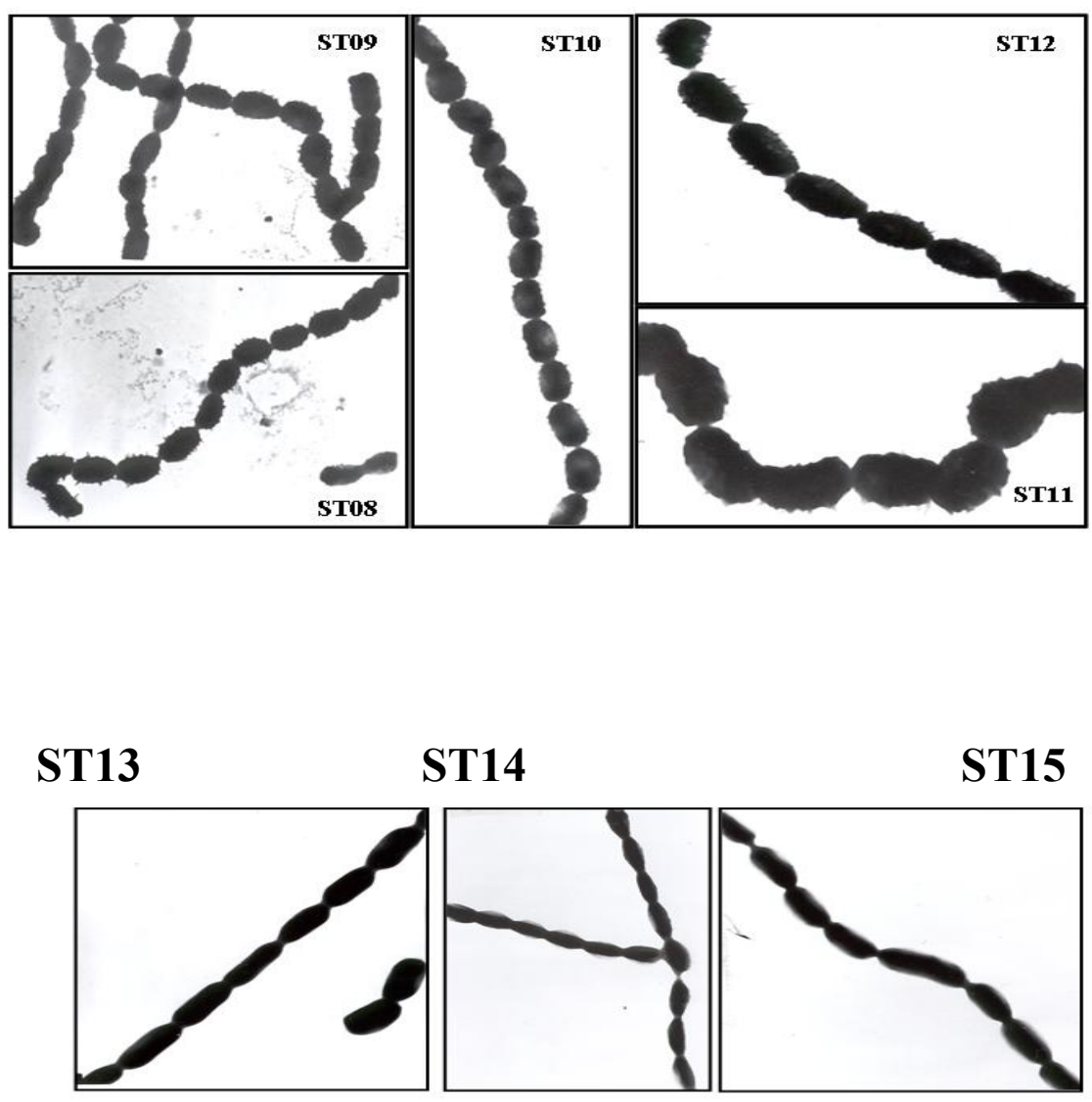

Figure 2. Electron micrographs (X-10000) of spore surface of some Streptomyces isolates. 
Arab Univ. J. Agric. Sci., Ain Shams Univ., Cairo, 13(3), 641-668, 2005

the utilization of sucrose, raffinose, rhamnose and fructose as sole carbon sources. Growth on Czapek's medium was moderate (ST10 and ST13), good (ST12) or excellent (ST11). They showed antagonistic activities against the bacterial test organisms except for ST10. They were also sensitive to streptomycin except for ST11.

All the isolates under investigation were able to grow in the presence of $10 \%$ $\mathrm{NaCl}$ in the growth medium and could not produce diffusible pigments.

\section{Numerical identification of the Streptomyces isolates}

According to the proposed numerical taxonomy in this study, cultural, morphological, physiological and antagonistic characteristics of the eight Streptomyces isolates and related Streptomyces species recorded in the proposed key of Pridham and Tresner (1974) were given 1 unit if present or 0 unit if absent. Scoring results for all characters of the eight Streptomyces isolates are given in Table (3). Accordingly, isolates numbers ST13, ST11, ST09, ST12, ST10, ST14, ST15 and ST08 had the following scoring in descending order, being 50, 50, 45, 45 , 42, 41, 40 and 40 units, respectively.

Clustering of all scoring units was determined (Sneath and Sokal, 1973) and the results as phylophenetic tree are given in Figure (3). The data reveal the presence of two major related clusters, one includes, ST08, ST09, ST14 and ST15 and the second includes ST10, ST11, ST12 and ST13. It was also found that each major cluster contained two subclusters. Subcluster A contained ST14 and ST15; subcluster B contained ST08 and ST09, subcluster C contained ST11 and ST13 and finally subcluster D contained ST10 and ST12.

\section{Numerical identification of white series isolates}

Characters of the three white Streptomyces isolates, namely, ST08, ST14 and ST15 and most similar Streptomyces species, i.e., S. albolongus, $S$. alboniger, $S$. baarnensis, $S$. longisporus and $S$. viridaris in the key proposed by Pridham and Tresner (1974) were scored (Tables 4 and 5).

The analysis of the scored data showed that ST08, ST14 and ST15 isolates were most related to $S$. longisporus, $S$. baarnensis and $S$. albolongus. Results in Table (6) and Figure (4) showed that ST08 \& $S$. longisporus; ST14 \& S. baarnensis and ST15 \& S. albolongus fell in three subclusters with similarities of 100, 95 and $91.1 \%$, respectively. However, slight differences were found between ST14 and $S$. baarnensis in the utilization of raffinose and antibacterial activities.

\section{Identification of red series isolates}

1- Agricultural Microbiology Department, Institute of Soil, Water and Environment Research, Agricultural Research Center, Giza, Egypt.

2- Agricultural Microbiology Department, Faculty of Agriculture, Ain Shams University, Shoubra El-Kheima, Cairo, Egypt 
The scored characters of the red ST09 Streptomyces isolate under investigation was compared with the scored characters of three red Streptomyces species, namely, $S$. purpurascens, $S$. yokosukanensis and $S$. janthinus in Pridham and Tresner (1974) key (Table 7). Result in Table (8) and Figure
(5) show that ST09 could be identified as a strain of $S$. janthinus with similarity of $95.8 \%$. The $4.2 \%$ differences between them could be due to the type of sporechain, growth on Czapek's medium, antagonistic activities and production of diffusible pigments as shown in Table (7). 
Arab Univ. J. Agric. Sci., Ain Shams Univ., Cairo, 13(3), 641-668, 2005

Table 3. Scoring of the characters of the eight Streptomyces isolates under investigation.

\begin{tabular}{|cccccccccc|}
\hline \multirow{2}{*}{ Characters } & \multicolumn{7}{c|}{ Streptomyces isolates } \\
\cline { 2 - 9 } & ST08 & ST09 & ST10 & ST11 & ST12 & ST13 & ST14 & ST15 \\
\hline a- Color of aerial mycelium (22) & 1 & 1 & 1 & 1 & 1 & 1 & 1 & 1 \\
& 1 & 1 & 1 & 1 & 1 & 1 & 1 & 1 \\
& 1 & 1 & 1 & 1 & 1 & 1 & 1 & 1 \\
& 1 & 1 & 1 & 1 & 1 & 1 & 1 & 1 \\
& 1 & 1 & 1 & 1 & 1 & 1 & 1 & 1 \\
& 1 & 1 & 1 & 1 & 1 & 1 & 1 & 1 \\
& 1 & 1 & 1 & 1 & 1 & 1 & 1 & 1 \\
& 1 & 1 & 1 & 1 & 1 & 1 & 1 & 1 \\
& 1 & 1 & 1 & 1 & 1 & 1 & 1 & 1 \\
c-Melanoid pigment (1) & 1 & 1 & 1 & 1 & 1 & 1 & 1 & 1 \\
& 1 & 1 & 1 & 1 & 1 & 1 & 1 & 1 \\
& 1 & 1 & 1 & 1 & 1 & 1 & 1 & 1 \\
& 1 & 1 & 1 & 1 & 1 & 1 & 1 & 1 \\
& 0 & 1 & 1 & 1 & 1 & 1 & 0 & 0 \\
& 0 & 1 & 1 & 1 & 1 & 1 & 0 & 0 \\
& 0 & 1 & 1 & 1 & 1 & 1 & 0 & 0 \\
& 0 & 0 & 1 & 1 & 1 & 1 & 0 & 0 \\
& 0 & 0 & 1 & 1 & 1 & 1 & 0 & 0 \\
& 0 & 0 & 1 & 1 & 1 & 1 & 0 & 0 \\
& 0 & 0 & 1 & 1 & 1 & 1 & 0 & 0 \\
& 0 & 0 & 1 & 1 & 1 & 1 & 0 & 0 \\
& 0 & 0 & 1 & 1 & 1 & 1 & 0 & 0 \\
& 1 & 1 & 1 & 1 & 1 & 1 & 1 & 1 \\
& 1 & 1 & 1 & 1 & 1 & 1 & 1 & 1 \\
& 0 & 1 & 0 & 1 & 0 & 1 & 1 & 1 \\
& 0 & 0 & 0 & 0 & 1 & 1 & 1 \\
& 1 & 1 & 1 & 1 & 0 & 1
\end{tabular}

1- Agricultural Microbiology Department, Institute of Soil, Water and Environment Research, Agricultural Research Center, Giza, Egypt.

2- Agricultural Microbiology Department, Faculty of Agriculture, Ain Shams University, Shoubra El-Kheima, Cairo, Egypt 
Table 3. Cont.

\begin{tabular}{|c|c|c|c|c|c|c|c|c|}
\hline \multirow[t]{2}{*}{ Characters } & \multicolumn{8}{|c|}{ Streptomyces isolates } \\
\hline & ST08 & ST09 & ST10 & ST11 & ST12 & ST13 & ST14 & ST15 \\
\hline \multicolumn{9}{|c|}{ e-Utilization of carbon compounds (17) } \\
\hline No carbon & 0 & 0 & 0 & 0 & 0 & 0 & 0 & 0 \\
\hline D-Glucose & 1 & 1 & 1 & 1 & 1 & 1 & 1 & 1 \\
\hline D-Xylose & 1 & 1 & 1 & 1 & 1 & 1 & 1 & 1 \\
\hline L-Arabinose & 1 & 1 & 1 & 1 & 1 & 1 & 1 & 1 \\
\hline \multirow[t]{2}{*}{ L-Rhamnose } & 1 & 1 & 1 & 1 & 0 & 1 & 1 & 1 \\
\hline & 1 & 1 & 1 & 1 & 0 & 1 & 1 & 1 \\
\hline \multirow[t]{2}{*}{ D-Fructose } & 1 & 1 & 1 & 0 & 1 & 0 & 1 & 1 \\
\hline & 1 & 1 & 1 & 0 & 1 & 0 & 1 & 1 \\
\hline \multirow[t]{2}{*}{ Raffinose } & 1 & 1 & 0 & 1 & 1 & 1 & 0 & 1 \\
\hline & 1 & 1 & 0 & 1 & 1 & 1 & 0 & 1 \\
\hline \multirow[t]{2}{*}{ D-Mannitol } & 1 & 1 & 1 & 1 & 1 & 1 & 0 & 0 \\
\hline & 1 & 1 & 1 & 1 & 1 & 1 & 0 & 0 \\
\hline \multirow[t]{2}{*}{ i-Inositol } & 1 & 1 & 1 & 1 & 1 & 1 & 1 & 1 \\
\hline & 1 & 1 & 1 & 1 & 1 & 1 & 1 & 1 \\
\hline \multirow[t]{3}{*}{ Sucrose } & 1 & 1 & 0 & 1 & 0 & 0 & 1 & 0 \\
\hline & 1 & 1 & 0 & 1 & 0 & 0 & 1 & 0 \\
\hline & 1 & 1 & 0 & 1 & 0 & 0 & 1 & 0 \\
\hline \multirow{5}{*}{$\begin{array}{l}\text { f- Growth on Czapek's medium } \\
\text { (5) }\end{array}$} & 1 & 1 & 1 & 1 & 1 & 1 & 1 & 1 \\
\hline & 1 & 1 & 1 & 1 & 1 & 1 & 1 & 1 \\
\hline & 1 & 1 & 1 & 1 & 1 & 1 & 1 & 1 \\
\hline & 1 & 1 & 0 & 1 & 1 & 0 & 1 & 1 \\
\hline & 1 & 0 & 0 & 1 & 0 & 0 & 1 & 0 \\
\hline \multirow[t]{2}{*}{ g- Anti-bacterial activity (2) } & 0 & 1 & 0 & 1 & 1 & 1 & 1 & 1 \\
\hline & 0 & 1 & 0 & 1 & 1 & 1 & 1 & 1 \\
\hline \multirow[t]{2}{*}{ h- Anti-fungal activity (2) } & 0 & 0 & 0 & 0 & 0 & 1 & 0 & 0 \\
\hline & 0 & 0 & 0 & 0 & 0 & 1 & 0 & 0 \\
\hline Total (58 Units) & 40 & 45 & 42 & 50 & 45 & 50 & 41 & 40 \\
\hline
\end{tabular}

1: Present. 0: Absent. 
Identification of streptomycete isolates by numerical taxonomy

Figure 3. Phylophenetic tree of eight Streptomyces isolates based on analysis of their selected characters. 
16

Mohamed; Saleh and Zaki

Table 4. Scoring of the characters of ST08 isolate compared with those of related species in Pridham and Tresner (1974) key.

\begin{tabular}{|c|c|c|c|c|}
\hline \multirow[t]{2}{*}{ Characters } & \multirow[t]{2}{*}{$\begin{array}{l}\text { ST08 } \\
\text { isolate }\end{array}$} & \multicolumn{3}{|c|}{$\begin{array}{c}\text { Streptomyces species in Pridham and } \\
\text { Tresner (1974) key }\end{array}$} \\
\hline & & S. alboniger & $\begin{array}{c}S . \\
\text { longisporus }\end{array}$ & S. viridaris \\
\hline \multirow[t]{22}{*}{ a- Color of aerial mycelium (22) } & 1 & 1 & 1 & 1 \\
\hline & 1 & 1 & 1 & 1 \\
\hline & 1 & 1 & 1 & 1 \\
\hline & 1 & 1 & 1 & 1 \\
\hline & 1 & 1 & 1 & 1 \\
\hline & 1 & 1 & 1 & 1 \\
\hline & 1 & 1 & 1 & 1 \\
\hline & 1 & 1 & 1 & 1 \\
\hline & 1 & 1 & 1 & 1 \\
\hline & 1 & 1 & 1 & 1 \\
\hline & 1 & 1 & 1 & 1 \\
\hline & 1 & 1 & 1 & 1 \\
\hline & 1 & 1 & 1 & 1 \\
\hline & 0 & 0 & 0 & 0 \\
\hline & 0 & 0 & 0 & 0 \\
\hline & 0 & 0 & 0 & 0 \\
\hline & 0 & 0 & 0 & 0 \\
\hline & 0 & 0 & 0 & 0 \\
\hline & 0 & 0 & 0 & 0 \\
\hline & 0 & 0 & 0 & 0 \\
\hline & 0 & 0 & 0 & 0 \\
\hline & 0 & 0 & 0 & 0 \\
\hline \multirow[t]{4}{*}{ b-Spore-chain (4) } & 1 & 1 & 1 & 1 \\
\hline & 1 & 1 & 1 & 1 \\
\hline & 0 & 1 & 0 & 1 \\
\hline & 0 & 1 & 0 & 1 \\
\hline c-Melanoid pigment (1) & 1 & 0 & 1 & 1 \\
\hline \multirow[t]{5}{*}{ d-Spore surface (5) } & 1 & 1 & 1 & 1 \\
\hline & 1 & 1 & 1 & 1 \\
\hline & 1 & 1 & 1 & 1 \\
\hline & 0 & 1 & 0 & 1 \\
\hline & 0 & 1 & 0 & 1 \\
\hline
\end{tabular}

Arab Univ. J. Agric. Sci., 13(3), 2005 
17

Identification of streptomycete isolates by numerical taxonomy

Table 4. Cont.

\begin{tabular}{|c|c|c|c|c|}
\hline \multirow[t]{2}{*}{ Characters } & \multirow[t]{2}{*}{$\begin{array}{l}\text { ST08 } \\
\text { isolate }\end{array}$} & \multicolumn{3}{|c|}{$\begin{array}{c}\text { Streptomyces species in Pridham and } \\
\text { Tresner (1974) key }\end{array}$} \\
\hline & & S. alboniger & $\begin{array}{c}\text { S. } \\
\text { longisporus }\end{array}$ & S. viridaris \\
\hline \multicolumn{5}{|c|}{ e- Utilization of carbon compounds (17) } \\
\hline No carbon & 0 & 0 & 0 & 0 \\
\hline D-Glucose & 1 & 1 & 1 & 0 \\
\hline D-Xylose & 1 & 1 & 1 & 1 \\
\hline L-Arabinose & 1 & 1 & 1 & 0 \\
\hline \multirow[t]{2}{*}{ L-Rhamnose } & 1 & 0 & 1 & 1 \\
\hline & 1 & 0 & 1 & 1 \\
\hline \multirow[t]{2}{*}{ D-Fructose } & 1 & 1 & 1 & 0 \\
\hline & 1 & 1 & 1 & 0 \\
\hline \multirow[t]{2}{*}{ Raffinose } & 1 & 0 & 1 & 1 \\
\hline & 1 & 0 & 1 & 1 \\
\hline \multirow[t]{2}{*}{ D-Mannitol } & 1 & 1 & 1 & 0 \\
\hline & 1 & 1 & 1 & 0 \\
\hline \multirow[t]{2}{*}{ i-Inositol } & 1 & 1 & 1 & 0 \\
\hline & 1 & 1 & 1 & 0 \\
\hline \multirow[t]{3}{*}{ Sucrose } & 1 & 0 & 1 & 1 \\
\hline & 1 & 0 & 1 & 1 \\
\hline & 1 & 0 & 1 & 1 \\
\hline \multirow[t]{5}{*}{ f- Growth on Czapek's meium (5) } & 1 & 0 & 1 & 1 \\
\hline & 1 & 0 & 1 & 1 \\
\hline & 1 & 0 & 1 & 1 \\
\hline & 1 & 0 & 1 & 1 \\
\hline & 1 & 0 & 1 & 1 \\
\hline \multirow[t]{2}{*}{ g- Anti-bacterial activity (2) } & 0 & 1 & 0 & 1 \\
\hline & 0 & 1 & 0 & 1 \\
\hline \multirow[t]{2}{*}{ h- Anti-fungal activity (2) } & 0 & 0 & 0 & 0 \\
\hline & 0 & 0 & 0 & 0 \\
\hline Total (58 Units) & 40 & 33 & 40 & 38 \\
\hline
\end{tabular}

1: Present.0: Absent. 
18

Mohamed; Saleh and Zaki

Table 5. Scoring of the characters of white ST14 and ST15 isolates compared with those of related species in Pridham and Tresner (1974) key.

\begin{tabular}{|c|c|c|c|c|}
\hline \multirow[t]{2}{*}{ Characters } & \multirow[t]{2}{*}{ ST14 } & \multicolumn{2}{|c|}{$\begin{array}{c}\text { Streptomyces species in } \\
\text { Pridham and Tresner (1974) } \\
\text { key } \\
\end{array}$} & \multirow[t]{2}{*}{ ST15 } \\
\hline & & S. albolongus & S. baarnensis & \\
\hline \multirow[t]{22}{*}{ a- Color of aerial mycelium (22) } & 1 & 1 & 1 & 1 \\
\hline & 1 & 1 & 1 & 1 \\
\hline & 1 & 1 & 1 & 1 \\
\hline & 1 & 1 & 1 & 1 \\
\hline & 1 & 1 & 1 & 1 \\
\hline & 1 & 1 & 1 & 1 \\
\hline & 1 & 1 & 1 & 1 \\
\hline & 1 & 1 & 1 & 1 \\
\hline & 1 & 1 & 1 & 1 \\
\hline & 1 & 1 & 1 & 1 \\
\hline & 1 & 1 & 1 & 1 \\
\hline & 1 & 1 & 1 & 1 \\
\hline & 1 & 1 & 1 & 1 \\
\hline & 0 & 0 & 0 & 0 \\
\hline & 0 & 0 & 0 & 0 \\
\hline & 0 & 0 & 0 & 0 \\
\hline & 0 & 0 & 0 & 0 \\
\hline & 0 & 0 & 0 & 0 \\
\hline & 0 & 0 & 0 & 0 \\
\hline & 0 & 0 & 0 & 0 \\
\hline & 0 & 0 & 0 & 0 \\
\hline & 0 & 0 & 0 & 0 \\
\hline \multirow[t]{4}{*}{ b-Spore-chain (4) } & 1 & 1 & 1 & 1 \\
\hline & 1 & 1 & 1 & 1 \\
\hline & 1 & 1 & 1 & 1 \\
\hline & 1 & 1 & 1 & 1 \\
\hline c-Melanoid pigment (1) & 0 & 1 & 0 & 1 \\
\hline \multirow[t]{5}{*}{ d-Spore surface (5) } & 1 & 1 & 1 & 1 \\
\hline & 1 & 1 & 1 & 1 \\
\hline & 1 & 1 & 1 & 1 \\
\hline & 1 & 1 & 1 & 1 \\
\hline & 1 & 1 & 1 & 1 \\
\hline
\end{tabular}

Arab Univ. J. Agric. Sci., 13(3), 2005 
Identification of streptomycete isolates by numerical taxonomy

Arab Univ. J. Agric. Sci., 13(3), 2005 
Table 5. Cont.

\begin{tabular}{|c|c|c|c|c|}
\hline \multirow[t]{2}{*}{ Characters } & \multirow[t]{2}{*}{ ST14 } & \multicolumn{2}{|c|}{$\begin{array}{c}\text { Streptomyces species in } \\
\text { Pridham and Tresner (1974) } \\
\text { key }\end{array}$} & \multirow[t]{2}{*}{ ST15 } \\
\hline & & \multicolumn{2}{|c|}{ S. albolongus S. baarnensis } & \\
\hline \multicolumn{5}{|c|}{ e- Utilization of carbon compounds (17) } \\
\hline No carbon & 0 & 0 & 0 & 0 \\
\hline D-Glucose & 1 & 1 & 1 & 1 \\
\hline D-Xylose & 1 & 1 & 1 & 1 \\
\hline L-Arabinose & 1 & 1 & 1 & 1 \\
\hline \multirow[t]{2}{*}{ L-Rhamnose } & 1 & 0 & 1 & 1 \\
\hline & 1 & 0 & 1 & 1 \\
\hline \multirow[t]{2}{*}{ D-Fructose } & 1 & 1 & 1 & 1 \\
\hline & 1 & 1 & 1 & 1 \\
\hline \multirow[t]{2}{*}{ Raffinose } & 1 & 0 & 0 & 1 \\
\hline & 1 & 0 & 0 & 1 \\
\hline \multirow[t]{2}{*}{ D-Mannitol } & 1 & 1 & 1 & 0 \\
\hline & 1 & 1 & 1 & 0 \\
\hline \multirow[t]{2}{*}{ i-Inositol } & 1 & 1 & 1 & 1 \\
\hline & 1 & 1 & 1 & 1 \\
\hline \multirow[t]{3}{*}{ Sucrose } & 0 & 0 & 0 & 0 \\
\hline & 0 & 0 & 0 & 0 \\
\hline & 0 & 0 & 0 & 0 \\
\hline \multirow[t]{5}{*}{ f- Growth on Czapek's medium (5) } & 1 & 1 & 1 & 1 \\
\hline & 1 & 1 & 1 & 1 \\
\hline & 1 & 1 & 1 & 1 \\
\hline & 1 & 1 & 1 & 1 \\
\hline & 1 & 1 & 1 & 0 \\
\hline \multirow[t]{2}{*}{ g- Anti-bacterial activity (2) } & 1 & 1 & 0 & 1 \\
\hline & 1 & 1 & 0 & 1 \\
\hline \multirow[t]{2}{*}{ h- Anti-fungal activity (2) } & 0 & 0 & 0 & 0 \\
\hline & 0 & 0 & 0 & 0 \\
\hline Total (58 Units) & 42 & 39 & 38 & 40 \\
\hline
\end{tabular}

1: Present. 0: Absent. 
Identification of streptomycete isolates by numerical taxonomy

Table 6. Similarities between the white Streptomyces isolates and related species in Pridham and Tresner (1974) key.

\begin{tabular}{|lccccc|}
\hline \multirow{2}{*}{$\begin{array}{l}\text { Streptomyces } \\
\text { isolates }\end{array}$} & \multicolumn{5}{c|}{} \\
& \multicolumn{6}{c|}{ Related white } & Streptomycetes species in Pridham and Tresner (1974) key \\
\cline { 2 - 6 } & S. longisporus & S. baarnensis & S. albolongus & S. viridaris & S. alboniger \\
\hline ST08 & $\mathbf{1 0 0}$ & 87.2 & 83.5 & 82.1 & 74.0 \\
ST14 & 87.8 & $\mathbf{9 5 . 0}$ & 93.8 & 85.0 & 88.0 \\
ST15 & 85.0 & 89.7 & $\mathbf{9 1 . 1}$ & 87.2 & 84.9 \\
\hline
\end{tabular}

Bold number represents the most similar species.

$\begin{array}{llll}0.81 & 0.85 & 0.90 & 1.00\end{array}$

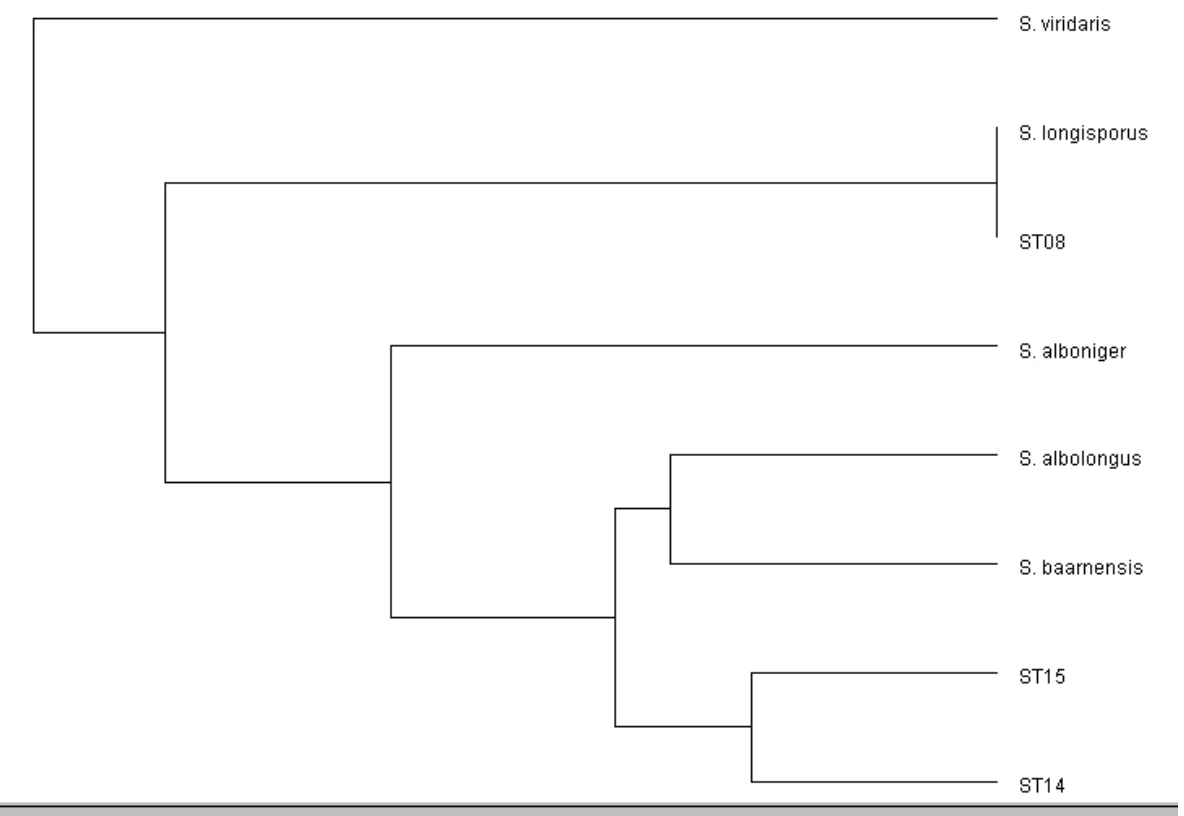

Figure 4. Phylophenetic tree of three Streptomyces isolates belonging to white series and related species in Pridham and Tresner (1974).

Arab Univ. J. Agric. Sci., 13(3), 2005 
Mohamed; Saleh and Zaki

Table 7. Scoring of the characters of ST09 isolate compared with those of related species in Pridham and Tresner (1974) key.

\begin{tabular}{|c|c|c|c|c|}
\hline \multirow[t]{2}{*}{ Characters } & \multirow[t]{2}{*}{$\begin{array}{l}\text { ST09 } \\
\text { isolate }\end{array}$} & \multicolumn{3}{|c|}{$\begin{array}{l}\text { Streptomyces species in Pridham } \\
\text { and Tresner (1974) key }\end{array}$} \\
\hline & & S. janthinus & $\begin{array}{c}S . \\
\text { purpuras } \\
\text { ens } \\
\end{array}$ & $\begin{array}{c}S . \\
\text { yokosukane } \\
\text { nsis }\end{array}$ \\
\hline \multirow[t]{22}{*}{ a- Color of aerial mycelium (22) } & 1 & 1 & 1 & 1 \\
\hline & 1 & 1 & 1 & 1 \\
\hline & 1 & 1 & 1 & 1 \\
\hline & 1 & 1 & 1 & 1 \\
\hline & 1 & 1 & 1 & 1 \\
\hline & 1 & 1 & 1 & 1 \\
\hline & 1 & 1 & 1 & 1 \\
\hline & 1 & 1 & 1 & 1 \\
\hline & 1 & 1 & 1 & 1 \\
\hline & 1 & 1 & 1 & 1 \\
\hline & 1 & 1 & 1 & 1 \\
\hline & 1 & 1 & 1 & 1 \\
\hline & 1 & 1 & 1 & 1 \\
\hline & 1 & 1 & 1 & 1 \\
\hline & 1 & 1 & 1 & 1 \\
\hline & 1 & 1 & 1 & 1 \\
\hline & 1 & 1 & 1 & 1 \\
\hline & 1 & 1 & 1 & 1 \\
\hline & 0 & 0 & 0 & 0 \\
\hline & 0 & 0 & 0 & 0 \\
\hline & 0 & 0 & 0 & 0 \\
\hline & 0 & 0 & 0 & 0 \\
\hline \multirow[t]{4}{*}{ b-Spore-chain (4) } & 1 & 1 & 1 & 1 \\
\hline & 1 & 1 & 1 & 1 \\
\hline & 1 & 0 & 0 & 0 \\
\hline & 0 & 0 & 0 & 0 \\
\hline c-Melanoid pigment (1) & 1 & 1 & 1 & 1 \\
\hline \multirow[t]{4}{*}{ d-Spore surface (5) } & 1 & 1 & 1 & 1 \\
\hline & 1 & 1 & 1 & 1 \\
\hline & 1 & 1 & 1 & 1 \\
\hline & 0 & 0 & 0 & 0 \\
\hline
\end{tabular}

Arab Univ. J. Agric. Sci., 13(3), 2005 
Identification of streptomycete isolates by numerical taxonomy 0 0 
Mohamed; Saleh and Zaki

Table 7. Cont.

\begin{tabular}{|c|c|c|c|c|}
\hline \multirow[t]{4}{*}{ Characters } & \multirow[t]{4}{*}{$\begin{array}{c}\text { ST09 } \\
\text { isolate }\end{array}$} & \multicolumn{3}{|c|}{$\begin{array}{c}\text { Streptomyces species in Pridham } \\
\text { and Tresner (1974) key }\end{array}$} \\
\hline & & \multirow{3}{*}{ S. janthinus } & & $S$ \\
\hline & & & purpurasc & yokosukane \\
\hline & & & ens & nsis \\
\hline \multicolumn{5}{|c|}{ e- Utilization of carbon compounds (17) } \\
\hline No carbon & 0 & 0 & 0 & 0 \\
\hline D-Glucose & 1 & 1 & 1 & 1 \\
\hline D-Xylose & 1 & 1 & 1 & 1 \\
\hline L-Arabinose & 1 & 1 & 1 & 1 \\
\hline \multirow[t]{2}{*}{ L-Rhamnose } & 1 & 1 & 1 & 1 \\
\hline & 1 & 1 & 1 & 1 \\
\hline \multirow[t]{2}{*}{ D-Fructose } & 1 & 1 & 1 & 1 \\
\hline & 1 & 1 & 1 & 1 \\
\hline \multirow[t]{2}{*}{ Raffinose } & 1 & 1 & 1 & 1 \\
\hline & 1 & 1 & 1 & 1 \\
\hline \multirow[t]{2}{*}{ D-Mannitol } & 1 & 1 & 1 & 1 \\
\hline & 1 & 1 & 1 & 1 \\
\hline \multirow[t]{2}{*}{ i-Inositol } & 1 & 1 & 1 & 1 \\
\hline & 1 & 1 & 1 & 1 \\
\hline \multirow[t]{3}{*}{ Sucrose } & 1 & 1 & 1 & 1 \\
\hline & 1 & 1 & 1 & 1 \\
\hline & 1 & 1 & 1 & 1 \\
\hline \multirow{5}{*}{ f- Growth on Czapek's medium (5) } & 1 & 1 & 0 & 1 \\
\hline & 1 & 1 & 0 & 1 \\
\hline & 1 & 1 & 0 & 0 \\
\hline & 1 & 1 & 0 & 0 \\
\hline & 0 & 1 & 0 & 0 \\
\hline \multirow[t]{2}{*}{ g- Anti-bacterial activity } & 1 & 1 & 1 & 1 \\
\hline & 1 & 1 & 1 & 1 \\
\hline \multirow{2}{*}{ h- Anti-fungal activity } & 0 & 1 & 0 & 1 \\
\hline & 0 & 1 & 0 & 1 \\
\hline Total (58 Units) & 45 & 47 & 40 & 44 \\
\hline
\end{tabular}

1: Present.0: Absent.

Table 8. Similarities between the red Streptomyces isolate and those related species in Pridham and Tresner (1974) key.

\begin{tabular}{|lccc|}
\hline $\begin{array}{c}\text { Streptomyces } \\
\text { Isolate }\end{array}$ & \multicolumn{3}{c|}{$\begin{array}{c}\text { Related red Streptomyces species in Pridham and Tresner (1974) } \\
\text { key }\end{array}$} \\
\cline { 2 - 4 } & S. janthinus & S. yokosukanensis & S. purpurascens \\
\hline ST09 & $\mathbf{9 5 . 8}$ & 94.6 & 94.4 \\
\hline
\end{tabular}

Arab Univ. J. Agric. Sci., 13(3), 2005 
Identification of streptomycete isolates by numerical taxonomy

Bold number represents the most similar species.

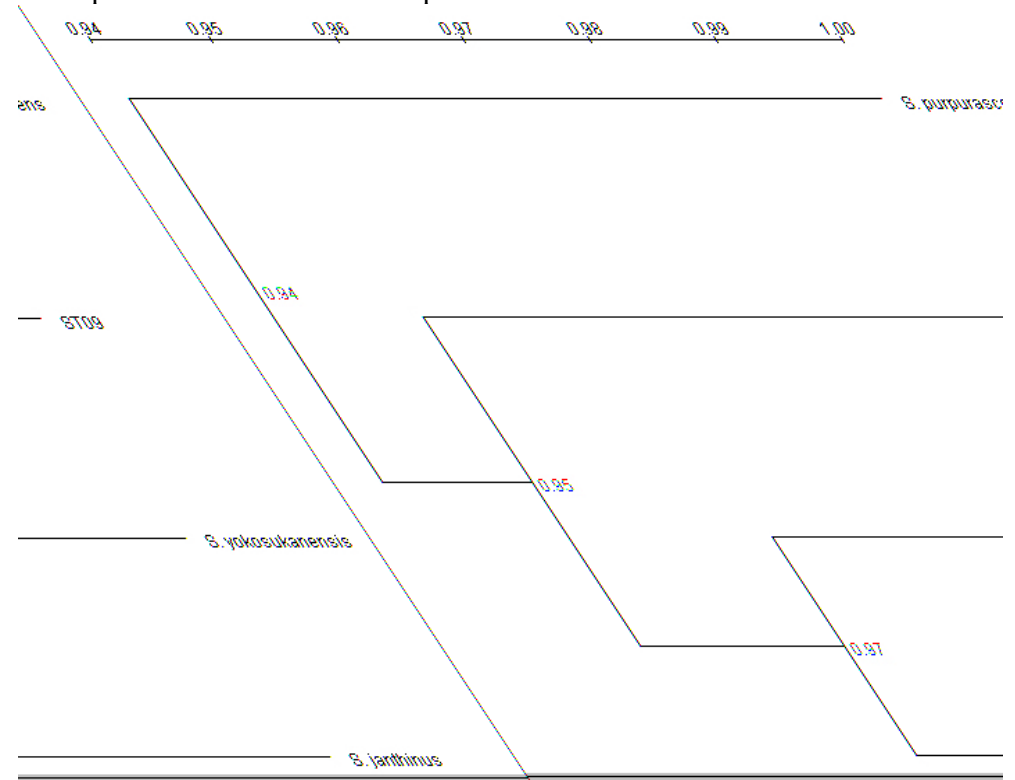

Figure 5. Phylophenetic tree of ST09 isolate belonging to red series and related species in Pridham and Tresner (1974).

\section{Identification of gray series isolates}

Characters of ten gray streptomycetes, i.e., the four isolates under investigation (ST10, ST11, ST12 and ST13) and most related six species in the key of Pridham and Tresner (1974) (S. durhamensis, $S$. filipinensis, $S$. griseochromogenes, $S$. chromofuscus, S. echinatus and $S$. antibioticus) were scored (Tables 9 and 10). Clustering (Figure 6) and similarities (Table 11) analyses showed that ST11 and ST13 isolates were strains of $S$. griseochromogenes, and $S$. antibioticus with similarities of 95.0 and $92.8 \%$, respectively. Isolates ST10 and ST12 were duplicate strains of $S$. echinatus with similarities of 93.3 and $94.6 \%$, respectively. This result confirmed the previous results in Figure
(3). As these two Streptomyces isolates were fell in one subcluster with a similarity of $92 \%$.

Streptomyces isolate ST11 differed from $S$. griseochromogenes in the utilization of L-rhamnose and fructose as sole carbon sources and color of substrate mycelium. ST11 tolerated the presence of $\mathrm{NaCl}$ up to $10 \%$ in the growth medium, while, S. griseochromogenes did not. There were some differences between ST13 and S. antibioticus, in utilization of raffinose, D-fructose, growth on Czapek's medium, antagonistic activities and salt tolerance (Table 9).

Application of the suggested numerical taxonomy on some known Streptomyces species 
Arab Univ. J. Agric. Sci., Ain Shams Univ., Cairo, 13(3), 641-668, 2005

The suggested numerical taxomomy under investigation was applied for

1- Agricultural Microbiology Department, Institute of Soil, Water and Environment Research, Agricultural Research Center, Giza, Egypt.

2- Agricultural Microbiology Department, Faculty of Agriculture, Ain Shams University, Shoubra El-Kheima, Cairo, Egypt 
Arab Univ. J. Agric. Sci., Ain Shams Univ., Cairo, 13(3), 641-668, 2005

Table 9. Scoring of the characters of ST11 isolate compared with those of related species in Pridham and Tresner (1974) key.

\begin{tabular}{|c|c|c|c|c|}
\hline \multirow[t]{2}{*}{ Characters } & \multirow[t]{2}{*}{$\begin{array}{l}\text { ST11 } \\
\text { isolate }\end{array}$} & \multicolumn{3}{|c|}{$\begin{array}{l}\text { Streptomyces species in Pridham and Tresner } \\
(\mathbf{1 9 7 4 )} \text { key }\end{array}$} \\
\hline & & S. durhamensis & $\begin{array}{c}S . \\
\text { filipinensis }\end{array}$ & $\begin{array}{c}S . \\
\text { griseochromogenes }\end{array}$ \\
\hline \multirow{22}{*}{$\begin{array}{l}\text { a- Color of aerial mycelium } \\
(22)\end{array}$} & 1 & 1 & 1 & 1 \\
\hline & 1 & 1 & 1 & 1 \\
\hline & 1 & 1 & 1 & 1 \\
\hline & 1 & 1 & 1 & 1 \\
\hline & 1 & 1 & 1 & 1 \\
\hline & 1 & 1 & 1 & 1 \\
\hline & 1 & 1 & 1 & 1 \\
\hline & 1 & 1 & 1 & 1 \\
\hline & 1 & 1 & 1 & 1 \\
\hline & 1 & 1 & 1 & 1 \\
\hline & 1 & 1 & 1 & 1 \\
\hline & 1 & 1 & 1 & 1 \\
\hline & 1 & 1 & 1 & 1 \\
\hline & 1 & 1 & 1 & 1 \\
\hline & 1 & 1 & 1 & 1 \\
\hline & 1 & 1 & 1 & 1 \\
\hline & 1 & 1 & 1 & 1 \\
\hline & 1 & 1 & 1 & 1 \\
\hline & 1 & 1 & 1 & 1 \\
\hline & 1 & 1 & 1 & 1 \\
\hline & 1 & 1 & 1 & 1 \\
\hline & 1 & 1 & 1 & 1 \\
\hline \multirow[t]{4}{*}{ b-Spore-chain (4) } & 1 & 1 & 1 & 1 \\
\hline & 1 & 1 & 1 & 1 \\
\hline & 1 & 1 & 1 & 1 \\
\hline & 0 & 0 & 1 & 0 \\
\hline
\end{tabular}

1- Agricultural Microbiology Department, Institute of Soil, Water and Environment Research, Agricultural Research Center, Giza, Egypt.

2- Agricultural Microbiology Department, Faculty of Agriculture, Ain Shams University, Shoubra El-Kheima, Cairo, Egypt 
Mohamed; Saleh and Zaki 
Identification of streptomycete isolates by numerical taxonomy

Table 9. Cont.

\begin{tabular}{|c|c|c|c|c|}
\hline \multirow[t]{2}{*}{ Characters } & \multirow[t]{2}{*}{$\begin{array}{l}\text { ST11 } \\
\text { isolate }\end{array}$} & \multicolumn{3}{|c|}{$\begin{array}{l}\text { Streptomyces species in Pridham and Tresner } \\
\text { (1974) key }\end{array}$} \\
\hline & & \multicolumn{3}{|c|}{$\begin{array}{lcc}\text { S. durhamensis } & S . & S . \\
& \text { filipinensis griseochromogenes }\end{array}$} \\
\hline \multicolumn{5}{|c|}{ e- Utilization of carbon compounds (17) } \\
\hline No carbon & 0 & 0 & 0 & 0 \\
\hline D-Glucose & 1 & 1 & 1 & 1 \\
\hline D-Xylose & 1 & 1 & 1 & 1 \\
\hline L-Arabinose & 1 & 1 & 1 & 1 \\
\hline \multirow[t]{2}{*}{ L-Rhamnose } & 1 & 0 & 0 & 0 \\
\hline & 1 & 0 & 0 & 0 \\
\hline \multirow[t]{2}{*}{ D-Fructose } & 0 & 1 & 1 & 1 \\
\hline & 0 & 1 & 1 & 1 \\
\hline \multirow[t]{2}{*}{ Raffinose } & 1 & 1 & 1 & 1 \\
\hline & 1 & 1 & 1 & 1 \\
\hline \multirow[t]{2}{*}{ D-Mannitol } & 1 & 1 & 1 & 1 \\
\hline & 1 & 1 & 1 & 1 \\
\hline \multirow[t]{2}{*}{ i-Inositol } & 1 & 1 & 1 & 1 \\
\hline & 1 & 1 & 1 & 1 \\
\hline \multirow[t]{3}{*}{ Sucrose } & 1 & 0 & 1 & 1 \\
\hline & 1 & 0 & 1 & 1 \\
\hline & 1 & 0 & 1 & 1 \\
\hline \multirow{5}{*}{$\begin{array}{l}\text { F- Growth on Czapek's } \\
\text { medium (5) }\end{array}$} & 1 & 1 & 1 & 1 \\
\hline & 1 & 1 & 1 & 1 \\
\hline & 1 & 1 & 1 & 1 \\
\hline & 1 & 1 & 1 & 1 \\
\hline & 1 & 1 & 1 & 1 \\
\hline \multirow[t]{2}{*}{ g- Anti-bacterial activity (2) } & 1 & 0 & 0 & 1 \\
\hline & 1 & 0 & 0 & 1 \\
\hline \multirow[t]{2}{*}{ h- Anti-fungal activity (2) } & 0 & 1 & 1 & 0 \\
\hline & 0 & 1 & 1 & 0 \\
\hline Total (58 Units) & 49 & 47 & 51 & 50 \\
\hline
\end{tabular}

Arab Univ. J. Agric. Sci., 13(3), 2005 
Table 10. Scoring of the characters of ST10, ST12 and ST13 isolates compared with those of related species in Pridham and Tresner (1974) key.

\begin{tabular}{|c|c|c|c|c|c|c|}
\hline \multirow[t]{2}{*}{ Characters } & \multirow[t]{2}{*}{$\begin{array}{l}\text { ST10 } \\
\text { isolate }\end{array}$} & \multicolumn{3}{|c|}{$\begin{array}{c}\text { Streptomyces species in Pridham and } \\
\text { Tresner (1974) key } \\
\end{array}$} & \multirow[t]{2}{*}{$\begin{array}{l}\text { ST13 } \\
\text { isolate }\end{array}$} & \multirow[t]{2}{*}{$\begin{array}{l}\text { ST12 } \\
\text { isolate }\end{array}$} \\
\hline & & $\begin{array}{c}\text { S. } \\
\text { chromofuscus }\end{array}$ & $\begin{array}{c}S . \\
\text { echinatus }\end{array}$ & $\begin{array}{c}S . \\
\text { antibioticus }\end{array}$ & & \\
\hline \multirow[t]{22}{*}{ a- Color of aerial mycelium (22) } & 1 & 1 & 1 & 1 & 1 & 1 \\
\hline & 1 & 1 & 1 & 1 & 1 & 1 \\
\hline & 1 & 1 & 1 & 1 & 1 & 1 \\
\hline & 1 & 1 & 1 & 1 & 1 & 1 \\
\hline & 1 & 1 & 1 & 1 & 1 & 1 \\
\hline & 1 & 1 & 1 & 1 & 1 & 1 \\
\hline & 1 & 1 & 1 & 1 & 1 & 1 \\
\hline & 1 & 1 & 1 & 1 & 1 & 1 \\
\hline & 1 & 1 & 1 & 1 & 1 & 1 \\
\hline & 1 & 1 & 1 & 1 & 1 & 1 \\
\hline & 1 & 1 & 1 & 1 & 1 & 1 \\
\hline & 1 & 1 & 1 & 1 & 1 & 1 \\
\hline & 1 & 1 & 1 & 1 & 1 & 1 \\
\hline & 1 & 1 & 1 & 1 & 1 & 1 \\
\hline & 1 & 1 & 1 & 1 & 1 & 1 \\
\hline & 1 & 1 & 1 & 1 & 1 & 1 \\
\hline & 1 & 1 & 1 & 1 & 1 & 1 \\
\hline & 1 & 1 & 1 & 1 & 1 & 1 \\
\hline & 1 & 1 & 1 & 1 & 1 & 1 \\
\hline & 1 & 1 & 1 & 1 & 1 & 1 \\
\hline & 1 & 1 & 1 & 1 & 1 & 1 \\
\hline & 1 & 1 & 1 & 1 & 1 & 1 \\
\hline \multirow[t]{4}{*}{ b-Spore-chain (4) } & 1 & 1 & 1 & 1 & 1 & 1 \\
\hline & 1 & 1 & 1 & 1 & 1 & 1 \\
\hline & 0 & 0 & 1 & 1 & 1 & 1 \\
\hline & 0 & 0 & 1 & 1 & 1 & 1 \\
\hline c-Melanoid pigments (1) & 1 & 1 & 1 & 1 & 1 & 1 \\
\hline \multirow[t]{5}{*}{ d-Spore surface (5) } & 1 & 1 & 1 & 1 & 1 & 1 \\
\hline & 1 & 1 & 1 & 1 & 1 & 1 \\
\hline & 1 & 1 & 1 & 1 & 1 & 1 \\
\hline & 0 & 0 & 0 & 1 & 1 & 0 \\
\hline & 0 & 0 & 0 & 1 & 1 & 0 \\
\hline
\end{tabular}

Arab Univ. J. Agric. Sci., 13(3), 2005 
Table 10. Cont.

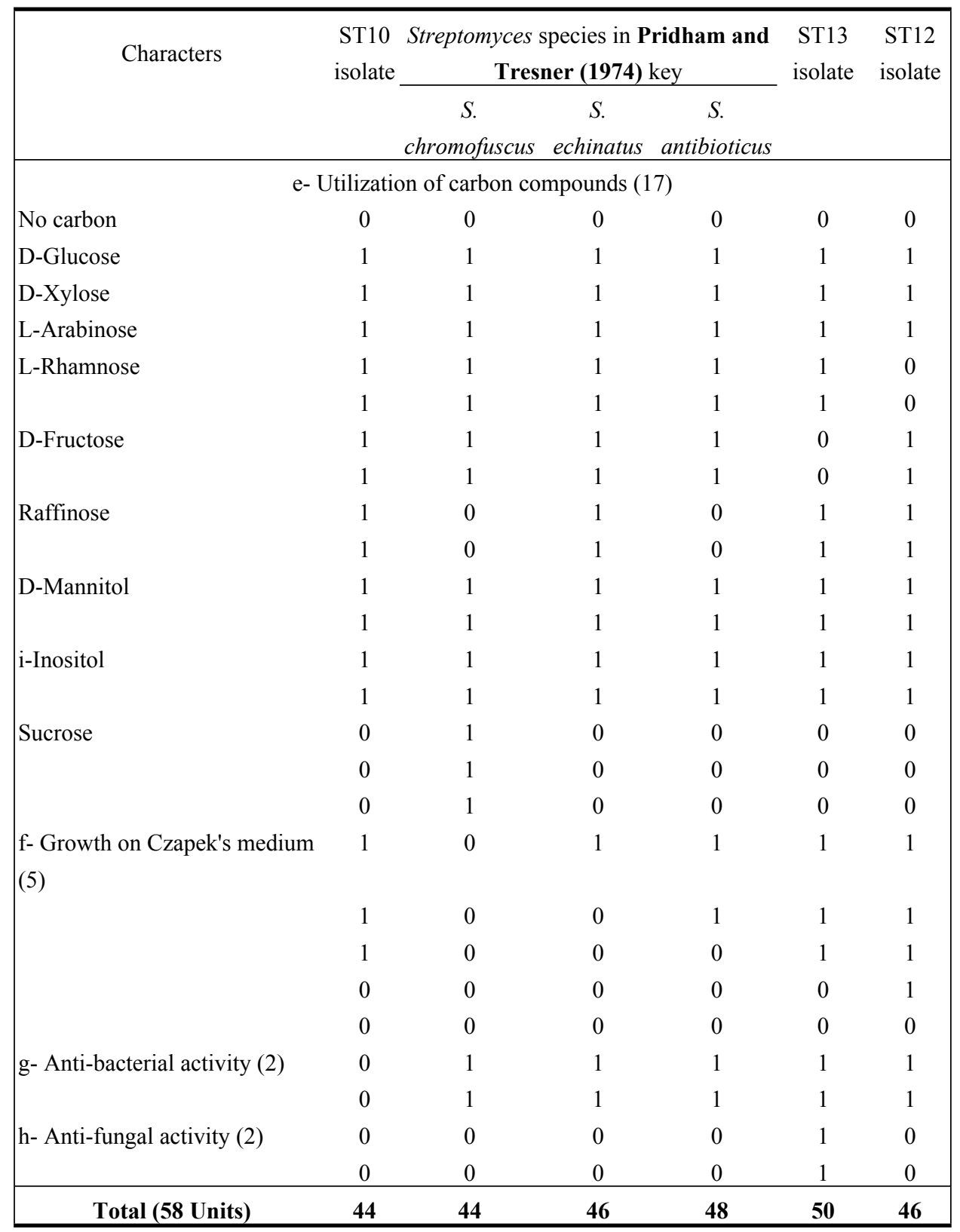

Arab Univ. J. Agric. Sci., 13(3), 2005 
Mohamed; Saleh and Zaki

Table 11. Similarities between the gray Streptomyces isolates and related species in Pridham and Tresner (1974) key.

\begin{tabular}{|c|c|c|c|c|c|c|}
\hline \multirow{2}{*}{$\begin{array}{c}\text { Streptomyces } \\
\text { isolates }\end{array}$} & \multicolumn{6}{|c|}{ Related gray Streptomycetes species in Pridham and Tresner (1974) key } \\
\hline & $\begin{array}{c}S . \\
\text { griseochrom } \\
\text { ogenes }\end{array}$ & $\begin{array}{c}\text { S. } \\
\text { echinatus }\end{array}$ & $\begin{array}{c}\text { S. } \\
\text { filipinensi } \\
S\end{array}$ & $\begin{array}{c}\text { S. } \\
\text { chromofus } \\
\text { cus }\end{array}$ & $\begin{array}{c}\text { S. } \\
\text { durhamen } \\
\text { sis }\end{array}$ & $\begin{array}{c}\text { S. } \\
\text { antibioticus }\end{array}$ \\
\hline ST10 & 88.4 & 93.3 & 87.5 & 88.6 & 91.3 & 90.1 \\
\hline ST11 & 95.0 & 90.2 & 89.6 & 89.4 & 87.8 & 86.6 \\
\hline ST12 & 93.9 & 94.6 & 90.9 & 85.7 & 92.6 & 91.5 \\
\hline ST13 & 87.1 & 91.7 & 88.2 & 83.0 & 89.8 & 92.8 \\
\hline
\end{tabular}

Bold number represents the most similar species.

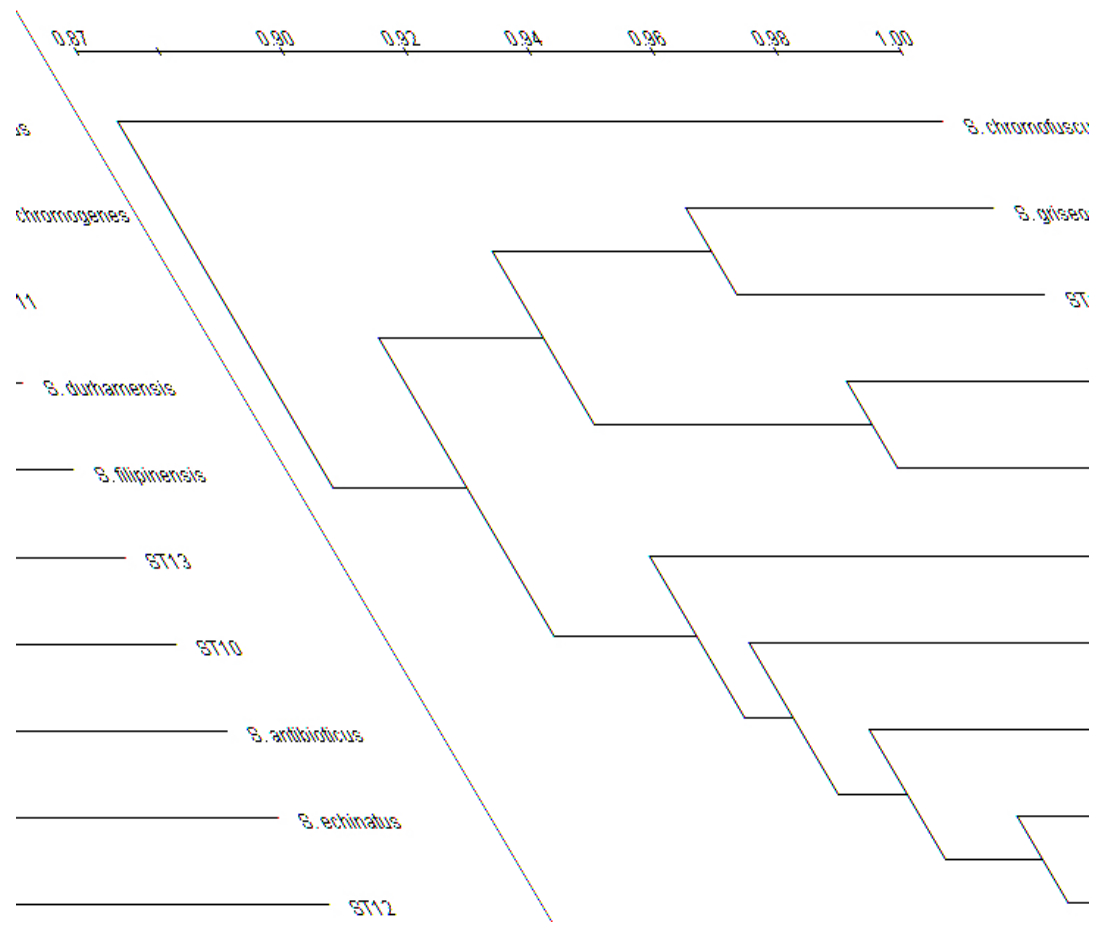

Arab Univ. J. Agric. Sci., 13(3), 2005 
33

Identification of streptomycete isolates by numerical taxonomy

Figure 6. Phylophenetic tree of four isolates belonging to gray series and related species in Pridham and Tresner (1974).

Arab Univ. J. Agric. Sci., 13(3), 2005 
Arab Univ. J. Agric. Sci., Ain Shams Univ., Cairo, 13(3), 641-668, 2005

determination of the relationship between the 14 known Streptomyces species used in the present study. Data presented in the phylophenetic tree (Figure 9) reveal that the Streptomyces species fell into three major clusters based on their color of aerial mycelia as follows:

First: includes white series species, i.e., $S$. viridaris, $S$. alboniger, $S$. baarnensis, S. albolongus and $S$. longisporus.

Second: includes red series species, i.e., S. purpurascens, S. yokosukanensis and $S$. janthinus
Third: includes gray series species, i.e., S. chromofuscus, $S$. antibioticus, $S$. echinatus, $S$. griseochromogenes, $S$. durhamensis and $S$. filipinensis.

Our results reveal that the suggested numerical taxonomy proved valiable as a base for the identification of Streptomyces. However, further studies are needed for more evaluation of this method by its application on the all known Streptomyces species presented in Pridham and Tresner (1974) key.

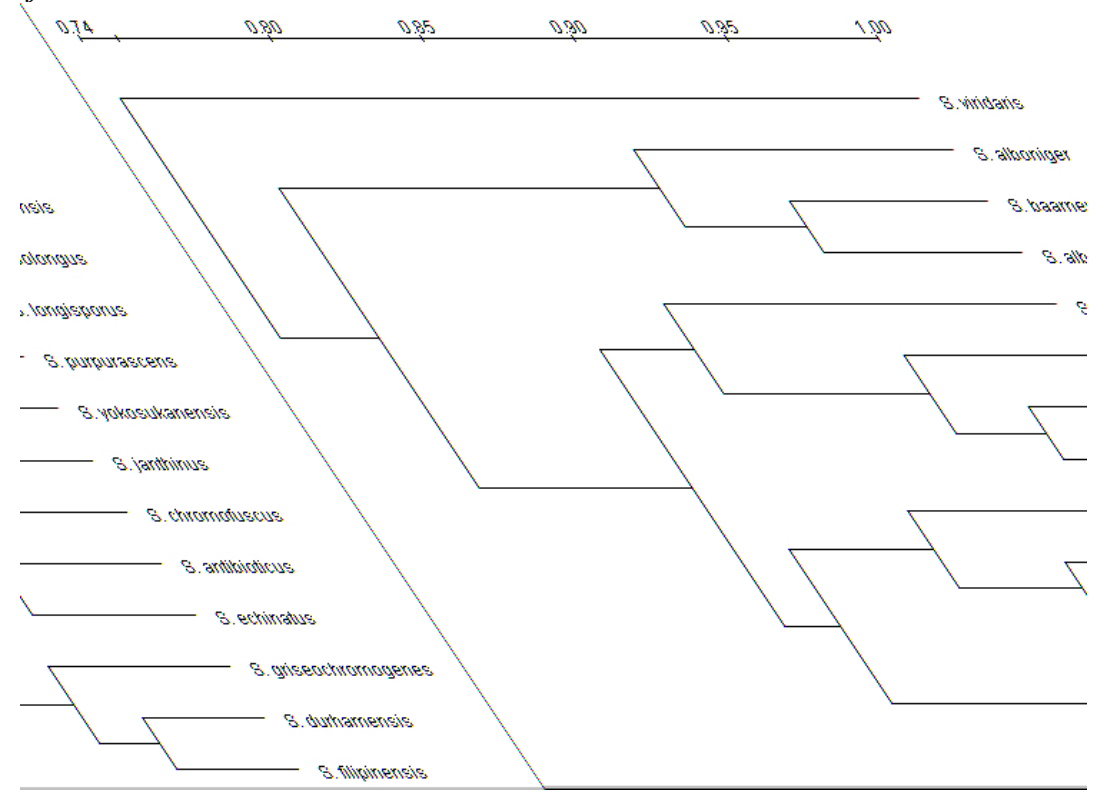

Figure 7. Phylophenetic tree of 14 Streptomyces species in the key of Pridham and Tresner (1974) achieved using suggested numerical taxonomy.

1- Agricultural Microbiology Department, Institute of Soil, Water and Environment Research, Agricultural Research Center, Giza, Egypt.

2- Agricultural Microbiology Department, Faculty of Agriculture, Ain Shams University, Shoubra El-Kheima, Cairo, Egypt 
Arab Univ. J. Agric. Sci., Ain Shams Univ., Cairo, 13(3), 641-668, 2005

\section{ACKNOWLEDGMENT}

The authors would like to thank Prof. Dr. Atef S. Sadik, Agric. Microbiol. Dept., Faculty of Agric., Ain Shams Univ. and Mr. Ahmed Fawzy, AGERI, ARC, Giza, Egypt for their sincere help to accomplish this study.

\section{REFERENCES}

\author{
Abdel-Fattah, H.I. (2005). Cultural, \\ morphological, physiological and \\ molecular studies on some streptomycete \\ isolates. Arab Univ. J. Agric. Sci., Ain \\ Shams Univ., Cairo, 13(2): 249-268. \\ Goodfellow M. (1967). Numerical \\ taxonomy of some named bacterial \\ cultures. Can. J. Microbiol. 13(10):1365- \\ 74. \\ Goodfellow, M.; G. Alderson and J. \\ Lacey (1979). Numerical taxonomy of \\ Actinomadura and related actinomycetes. \\ J. Gen. Microbiol. 112(1): 95-111. \\ Goodfellow, M.; J. Lacey and C. Todd \\ (1987). Numerical classification of \\ thermophilic streptomycetes. J Gen. \\ Microbiol. 133(11): 3135-3149. \\ Goodfellow, M.; E.V. Ferguson and \\ J.J. Sanglier (1992). Numerical \\ classification and identification of \\ Streptomyces species-a review. Gene \\ 115(1-2): 225-233. \\ Kurylowicz W.; A. Paszkiewicz; T. \\ Szulga; W. Woznicka and W.
}

Kurzatkowski (1975). Classification of streptomycetes by different numerical methods. Postepy. Hig. Med. Dosw. 197529(3): 281-355.

Mohamed, H. Sonya; Sh.M. Selim and E.A. Saleh (2000). Taxonomical and biochemical studies on some halotolerant actinomycetes isolated from sandy soil in Egypt. Arab Univ. J. Agric. Sci., Ain Shams Univ., Cairo 8(1): 41-61. Mohamed, H. Sonya; H.I. AbdelFattah; Sh.M. Selim and M.S. Sharaf (2001). Identification and molecular studies on some halotolerant actinomycetes isolated from Sinai sandy soil. Arab J. of Biotech. 4: 179-196. Paszkiewicz A. (1972). Application ofnumerical methods to the taxonomy of the genus Streptomyces. Arch. Immunol. Ther. Exp. (Warsz).20(3):307-32. Pridham, T.G. and H.D. Tresner (1974). Family Streptomycetacae. In; Bergey's Manual of Determinative Bacteriology (1974), p751, 793, 802 \& 826. (Buchanan R.E. and N.E. Gibbons, $8^{\text {th }} \quad$ Eds.), Williams and Wilkins, Baltmore, USA.

Saleh, E.A.; M.M. Zaki; M.E. ElDemerdash and Sonya H. Mohamed (1990). Identification of some halotolerant streptomycetes isolated from marine ecosystems in Egypt. Annals of Agric. Sci., Ain Shams Univ., Cairo, Special Issue, 409-425.

1- Agricultural Microbiology Department, Institute of Soil, Water and Environment Research, Agricultural Research Center, Giza, Egypt.

2- Agricultural Microbiology Department, Faculty of Agriculture, Ain Shams University, Shoubra El-Kheima, Cairo, Egypt 
Arab Univ. J. Agric. Sci., Ain Shams Univ., Cairo, 13(3), 641-668, 2005

Shirling, E.B. and D. Gottlieb (1966). Williams, S.T.; M. Goodfellow; G.

Methods for characterization of AlDerson; E.M.H. Wellington; P.H.A.

Streptomyces species. Int. J. Syst. Sneath and M.J. Sackin (1983).

Bacteriol. 16(3): 313-340.

Sneath, P.H.A. and R.R. Sokal (1973).

Numreical Taxonomy: The Principles and Practice of Numerical Classification, pp. 1-573. San Francisco: W.H. Freeman.

Numerical classification of Streptomyces and related genera J. Gen. Microbiol. 129 (6): 1743-1813.

Srinivasan, M.C.; R.S. Laxman and M.V. Deshpande (1991). Physiology and nutritional aspects of actinomycetes: an overview. World J. Microbiol. and Biotech. 7: 171-189. Williams, S.T.; M. Goodfellow and G. Alderson (1989). Genus Streptomyces. In: Bergey's Manual of Determinative Bacteriology. pp. 24522492. (Williams, S.T.; M.E. Sharpe and J.P. Holt eds), Williams and Wilkins, Baltimore, USA.

1- Agricultural Microbiology Department, Institute of Soil, Water and Environment Research, Agricultural Research Center, Giza, Egypt.

2- Agricultural Microbiology Department, Faculty of Agriculture, Ain Shams University, Shoubra El-Kheima, Cairo, Egypt 
Arab Univ. J. Agric. Sci., Ain Shams Univ., Cairo, 13(3), 641-668, 2005

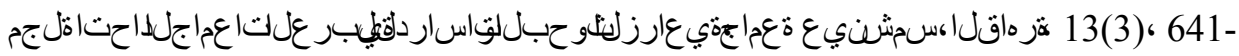
668، 2005

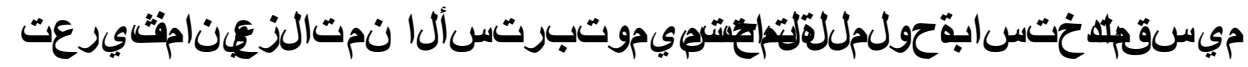

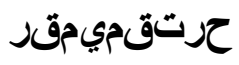

\section{]42[}

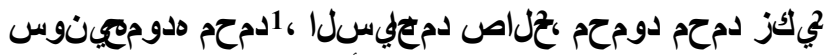

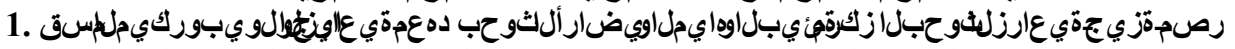

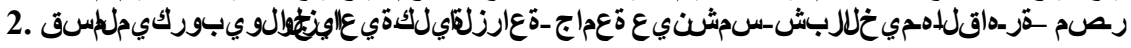

ST08, ST09, ST11,

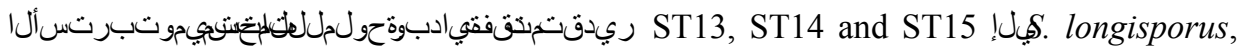

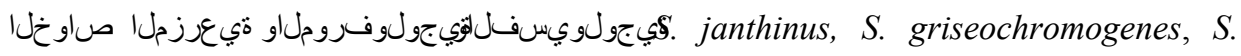
antibioticus $S$. baarnensis and $S$.

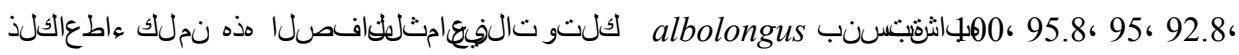

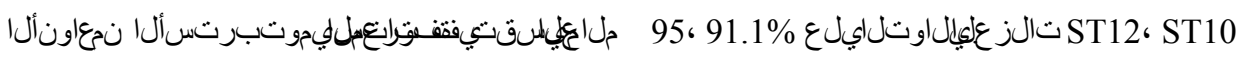
ثبسنب S. echinatus

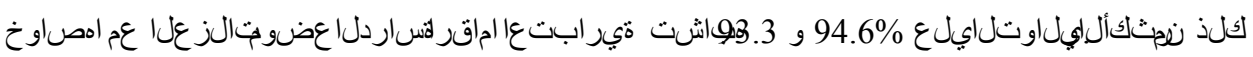

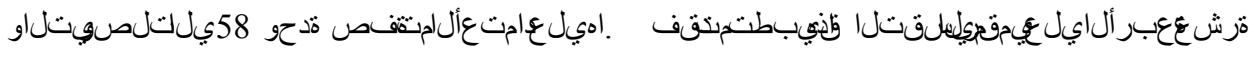

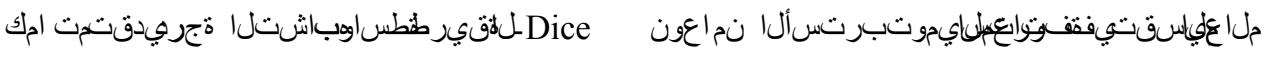

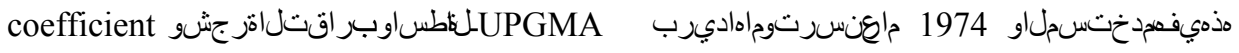
algorithm .

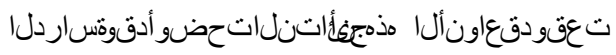

نجتفنير عتمثييمقرلةقير طلا ملثنختسابو

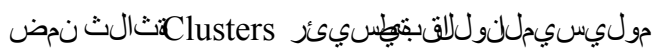

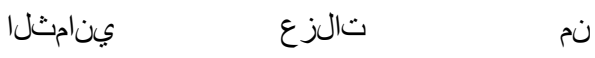

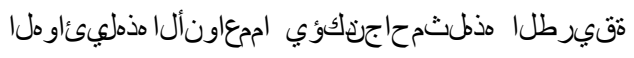

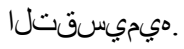

ىدمحيل فس

1- Agricultural Microbiology Department, Institute of Soil, Water and Environment Research, Agricultural Research Center, Giza, Egypt.

2- Agricultural Microbiology Department, Faculty of Agriculture, Ain Shams University, Shoubra El-Kheima, Cairo, Egypt 